\title{
Reviews
}

Managing Mental Health Services. London: The Institute of Health Services Management. 1991. Pp. 40. £6.95.

"I have intimated ... that in 15 years' time there may well be needed not more than half as many places in hospitals for mental illness as there are today ... these bold words imply nothing less than the elimination of by far the greater part of this country's mental hospitals as they exist today ... do not for a moment underestimate their powers of resistance to our assault".

These 'bold words' from Enoch Powell's address to a National Association for Mental Health conference in 1961 still ring with a tone of controlled outrage across the three decades that have since elapsed. Three decades which have seen the hospitals largely successful in their resistance to change. A recent review of mental health services conducted on behalf of the Department of Health, quoted in this report, revealed that in $1988 / 89$ over $60 \%$ of expenditure on mental health services in England and Wales was still spent on old institutions. This report, for which extracts from Powell's speech provide a foreword, should therefore be timely and relevant. It is unfortunately rather dull.

The problem may well be in the membership of the Project Group which produced the report, and their protracted deliberation. Despite the report being full of collaborative messages, such as "health, local authority and all agencies or groups must therefore have a stake in a joint agreed service strategy" and "involve service users", it was compiled by a group overwhelmingly comprised of past or present managers of health authority mental health units. This 'provider' dominance is reflected, for example, in a section about purchasing mental health services which runs to just two pages and which fails to address most of the key issues now being faced by contract managers responsible for purchasing psychiatric care.

The protracted life of the group, and the need for drafts to be approved by a committee, make the overall report feel rather tired, an impression not helped by a publishing format which is very 1970 s. This overall impact is in direct contrast to the urgency of the challenges faced by those pursuing improvement in mental health services, challenges which have been faced and to some extent overcome by individual members of the Project Group.

It is difficult to be clear about the audience that this report would enlighten or inspire. It is not one that should be sought out by consultant psychiatrists.

\section{Acting Head}

EDWARd PeCK

\section{Health Services Management Unit}

University of Newcastle upon Tyne

Consulting Consumers in the NHS: a guideline study. Services for elderly people with dementia living at home.

London: National Consumer Council. 1990.

Pp. 68.

Consumer choice, consumer rights and the involvement of consumers in planning and demanding value for money are very popular subjects, particularly in relationship to public services. In the Health Service very many individuals of varied professions and occupations have laboured hard over many years to ensure - or tried to ensure - that the consumers of the service had choice, value for money, were able to influence the development of services and could clearly express their views on what was, or was not provided. Recent statements by the administration and others would suggest that this had never been.

Allowing for the fact that the wheel has been discovered yet again, this publication by the National Consumer Council describes a well-designed and carried out study into what elderly people with dementing illness and their carers want from the Health Service and goes on to describe what should be provided and methods of measuring effectiveness, taking into consideration what is wanted and expected by the consumers. It was discovered, for example, that carers mentioned the following areas of need most frequently: early diagnosis (meaning what was wrong, what to expect, and what to plan for); information and advice; counselling; a sitting service; information about possible residential care (for long term planning); and a prompt, reliable ambulance service for those attending day units.

People working in the field should already know this to be the case but having it spelt out as a result of a well carried out survey gives these needs more significance and discovering them in the survey in no way detracts from the need and usefulness of such a survey.

One section of the report covers measuring effectiveness using check lists, questionnaires and performance indicators. This, like the rest of the report, is excellent and gives valuable information and very good questionnaires and check lists. 
In the section on conclusions, it is suggested that methods used in this survey and the types of indicators described could be extended to many other facets of the Health Service, including almost everything from paediatrics to Accident and Emergency facilities by way of maternity services and facilities for HIV positive individuals.

In my opinion, the National Consumer Council has done an excellent job and provided a very good instrument which must be read and consumed by the providers of services, particularly their managers and political masters. In the past, the discovery of need has too often led to experiments to prove the need had faded away, inadequate provision or a simple disregard for what people wanted. It is right and proper that the Health Service is efficient and cost effective but meeting the needs of our customers can be expensive and the concept of cost effectiveness can be taken and perverted to mean that certain things are not provided because they are costly and their efficacy is difficult to prove.

I hope that the National Consumer Council, or others, take up the idea of extending the work described to every other facet of the Health Service. I also hope that, with a faltering heart, the administration and management of the Health Service also takes seriously the findings of this report and the future hoped for reports.

\section{Consultant Psychiatrist \\ Brighton General Hospital \\ Brighton BN2 3EW}

\section{Psychiatric Service to Adult Mentally Retarded and Developmentally Disabled Persons.}

American Psychiatric Association Task Force, Report 30, 1400 K Street, NW, Washington

DC 20005. 1991. Pp. 29.

This is the last report in a monograph series published by the American Psychiatric Association, of a task force on Psychiatric Services for Adults with Mental Handicaps, set up in June 1988. The membership of the task force was chaired by Dr Ludwick Szymanski of the Children's Hospital, Boston, and included other prominent members such as Professor Frank Menalascino of the University of Nebraska.

The report comprises the following sections: Background, The Need for Psychiatric Services, Current Patterns of Care (Availability and Gaps), Training
Psychiatrists, Successful Models of Service, Future Roles of the APA, and Recommendations for Specific Actions.

The publication of this report confirms the importance the American Psychiatric Association gives to the problem of psychiatric services for people with mental handicaps in the United States.

Attention is drawn to a mail survey conducted by the task force in all states, which showed that psychiatric services were overwhelmingly provided by fee-paying consultants $(80 \%)$ while only $6 \%$ were employed as psychiatrists and $8 \%$ had no available psychiatric services at all. Virtually all states $(96 \%)$ said that they had difficulties in recruiting psychiatrists, mainly because of lack of specialist psychiatric training in mental handicap and lack of funding, including poor third party reimbursements.

Even more significant and troubling were the comments that psychiatrists were not interested in mental handicap because there is neither training in the American medical schools nor in psychiatric residencies. Psychiatrists also believed that psychiatric treatments in mental handicap (43\%) were not applicable except medication, and they were not able to work with people having non-verbal communication.

The report concludes by recommending ways in which the APA and psychiatrists can improve the provision of services to people with mental handicaps, including: changing attitudes, adapting to the needs of the field (eclecticity and inter-disciplinary collaboration), generic and specialist professional involvement and expertise, considering a spectrum of possible service models and funding arrangements, and finally, by the APA providing leadership to the psychiatric profession in setting standards of practice as well as promoting training, research, professional liaison and advocacy.

The report also highlights the great concern of the administrators to be able to recruit properly trained psychiatrists which is regarded as a necessary component for improving the quality of service and rightly emphasises the need for including specialist training in the curriculum of residency programmes.

This is an important publication for higher specialist training which will also be of interest to service planners and providers for people with mental handicap, and psychiatrists.

Consultant Psychiatrist

N. BOURAS

Guy's Hospital

London SE1 9RT 